\title{
“DE UM AVIÃO” DE CABRAL: IMPLICAÇÕES DE UMA LEITURA NEWTONIANA E DE UMA LEITURA RELATIVÍSTICA DE UM "AEROPOEMA"
}

\section{"De um avião" by Cabral: implications of a newtonian reading and a relativistic reading of an "Aeropoema"}

RESUMO: Analisaremos a composição “De um avião”, de João Cabral de Melo Neto, tendo em vista duas perspectivas (ou dois interpretantes): numa, que se manterá nos limites da física newtoniana, veremos que o texto desemboca num antropocentrismo de pequena compatibilidade com o descentramento que passou a associar-se à mesma física, depois que Freud tomou o heliocentrismo copernicano como um exemplo de "golpe" desferido pela realidade no narcisismo humano; noutra, que avançará pela teoria da relatividade, defenderemos que o que parece antropocentrismo é, afinal, compatível com o que Albert Einstein e Herman Minkowski descobriram em 1905 e 1907. Isto se fará possível porque a concepção de descentramento, válida em vários domínios, não o é no âmbito do relativismo einstein-minkowskiano, ao contrário do que pode fazer pensar o uso da mesma concepção a torto e a direito, no interior de não poucos discursos marcados pelo pós-modernismo.

Palavras-chave: poesia moderna; pós-modernismo; teoria da relatividade; filosofia da ciência; semiótica.

ABSTRACT: We analyse João Cabral de Melo Neto's work "De um avião" from two
perspectives (or two interpretants). Firstly, through the lenses of Newtonian physics,
we see that Cabral's text leads to an anthropocentrism that has little affinity with the
decentralisation usually related to such physics. This association has happened after
Freud used the Copernican heliocentrism as an example of a "coup" carried out by
reality on human's narcissism. Secondly, we employ relativity theory to support the
idea that what seems to be anthropocentrism is actually in line with Albert Einstein's
and Herman Minkowski's discoveries in 1905 and 1907. Those readings are possible
because the concept of decentralisation does not hold in the Einstein-Minkowski
relativism, even if it does so in several other domains, and differently from one might Revista Texto Poético | ISSN: 1808-5385 | Vol. 19 (2o sem-2015) - p. 191 
deduce from the indiscriminate use of that concept within several post-modern discourses.

Keywords: modern poetry; postmodernism; relativity theory; philosophy of science; semiotics.

\section{Propósitos gerais}

Iremos analisar o poema "De um avião", de João Cabral de Melo Neto, de dois modos principais.

No primeiro, efetuaremos uma interpretação que seguirá a modalidade mais ou menos costumeira de exegese, no terreno literário. Esta leitura inicial, todavia, irá fazer-nos desembocar, para além do terreno da literatura, nas perspectivas ao mesmo tempo antropocêntrica e newtoniana, o que resultará em um resultado contraditório, do ponto de vista de combinação, precisamente, dos dois últimos aspectos.

$\mathrm{Na}$ segunda empreitada interpretativa, tentaremos desenvolver uma abordagem que levará em conta a teoria da relatividade restrita, um dos pilares da física moderna, ou seja, das ciências naturais. Esta perspectiva irá pressupor uma visão mais ampla da realidade, que dirá respeito à localização do homem no universo, em termos de espaço e tempo, ou melhor, de contínuo espaço-tempo, descoberto por Albert Einstein e Hermann Minkowski, nos anos 1905-1907. Observaremos, então, que o antropocentrismo do poema é, afinal, compatível com a relatividade einstein-minkowskiana, ainda que esta não seja caracterizável propriamente como antropocêntrica (mas como multicentrada, segundo buscaremos mostrar). 


\section{Humanismo e física newtoniana}

"De um avião" é um poema do livro Quaderna, lançado em 1960, em Lisboa, com poemas datados de 1956-1957. Trata-se de um texto arabicamente dividido em cinco partes, cada uma delas com oito estrofes (organizadas em formato de dísticos octossilábicos e hexassilábicos, sempre nessa ordem). Como $8 \times 5=40$, temos, de saída, uma associação do seu número de versos com o título do volume - Quaderna - e com certa preferência de Cabral pelo algarismo 4. No prefácio que escreveu para a Obra completa da Nova Aguilar, lembra Marly de Oliveira: "Aliás, o número 4 e seus múltiplos são uma presença constante na poesia de João Cabral de Melo Neto, não que a ele atribua uma função esotérica, mas simplesmente como sinônimo de equilíbrio e racionalidade" (in MELO NETO, 1994, p. 20). Com ou sem "função esotérica", ser o 4 um tal "sinônimo" coloca a específica propensão numerológica de Cabral no país do simbolismo, indubitavelmente, menos espantoso, aliás, do que a cientificidade einsteiniana, mais estranha do qualquer esoterismo deste mundo, como observaremos à frente.

Antes de embarcarmos, todavia, em "De um avião", recordemos um mínimo da semiótica de Charles Sanders Peirce, parcela teórica adiante útil aos nossos intentos. Acompanhemos o seu triadismo, indo do signo ao interpretante, passando pelo objeto.

Há uma conceituação do filósofo mais complexa do que a que postula ser o signo algo (um Primeiro) que, de algum jeito, se acha no lugar de outro elemento (um Segundo, dito objeto), gerando um novo componente (um Terceiro, chamado interpretante) (PEIRCE, 1977 , p. 46; $C P, 2.228)$. Vejamos a conceituação, onde surge o termo Representâmen, de que Peirce se valerá, ora tendo nos seus

Revista Texto Poético | ISSN: 1808-5385 | Vol. 19 (2o sem-2015) - p. 193 
textos a acepção de "signo", ora a de "signo ainda não atualizado" (PINTO, 1995, p. 46):

Um Representâmen [Signo] é o Primeiro Correlato de uma relação triádica, o Segundo Correlato sendo chamado de seu Objeto e o possível Terceiro Correlato sendo denominado seu Interpretante, por cuja relação triádica o possivel Interpretante é determinado como sendo o Primeiro Correlato da mesma relação triádica para com o mesmo objeto para algum interpretante (apud SANTAELLA, 1995, p. 25; CP, 2.242).

Quanto ao objeto, ele passa por uma divisão, sendo imediato ou dinâmico, de acordo com o ponto de vista peirciano $(C P, 8.183$, 8.314).

Objeto imediato é o que se encontra disponível no signo do modo mais direto, situando-se no interior deste. Ele tem origem no objeto dinâmico (real ou imaginário), que, situado no exterior do signo, é o verdadeiro provocador da semiose (ou ação sígnica). No mundo, ao confrontarmo-nos com as coisas (concretas ou não) da realidade, às mesmas temos acesso à medida que as significamos; por tal razão, o objeto imediato resulta da manipulação mental a que as submetemos, na qualidade de animais semióticos. Objeto dinâmico é o objeto deflagrador da semiose. Abordamos essa espécie de objeto transmutando-o em signo, vale dizer, objeto imediato. $^{42}$

${ }^{42}$ Peirce pensou em outras divisões do objeto. $\mathrm{O}$ imediato poderia ser também: a) descritivo; b) designativo; c) copulante. Por sua vez, o dinâmico se tripartiria em: a) abstrativo; c) concretivo; c) coletivo (cf. SANTAELLA, 1995 , p. 57-58, 60).

Revista Texto Poético | ISSN: 1808-5385 | Vol. 19 (2o sem-2015) - p. 194 
O interpretante experimenta uma tripartição, sendo imediato, dinâmico ou final $(C P, 8.314) .{ }^{43} \mathrm{O}$ interpretante imediato concerne às possibilidades interpretativas do signo. Corresponde ao potencial de sentido que irá atuar em nosso comportamento, desde que tenhamos um mínimo conhecimento do objeto dinâmico (convertido em imediato) a que o signo envia. $\mathrm{O}$ interpretante dinâmico são as possibilidades interpretativas de fato selecionadas na utilização do signo, extraídas do conjunto de virtualidades significativas do interpretante imediato. Já o interpretante final diz respeito ao esgotamento das possibilidades interpretativas do signo. Uma hipótese que vislumbra um conhecimento pleno do objeto dinâmico, esgotando-o em termos de informação.

Com esta bagagem teórica inicial, embarquemos agora em "De um avião", na sua peculiaríssima lógica poética. De início, notemos com qual gênero o texto individual se relaciona.

Entusiasmados com a tecnologia da sua época, inclusive a da aeronáutica, os futuristas italianos compuseram o que se chama "aeropoema" (cf. FAUSTINO, 2004, p. 289-291), ou seja, textos escritos a partir de uma perspectiva aérea, de voo mecânico. "De um avião" claramente é um trabalho de tal espécie, embora sem o teor agressivo, "tecnofascista", que caracterizou boa parcela do futurismo na Itália. ${ }^{44}$ Trata-se de uma viagem "Pernambuco -

${ }^{43}$ Para outras tripartições do interpretante, cf. SANTAELLA, 1995, p. 83116.

${ }^{44} \mathrm{~F}$. T. Marinetti, compreensivelmente, esteve na vanguarda de tal gênero de escrita. Duas observações são interessantes aqui: a) o Manifesto técnico da literatura futurista, de autoria do próprio Marinetti, datado de 1912, é apresentado, poeticamente, como se o seu autor de fato se achasse num "aeroplano" e, mais interessante ainda, como se a "hélice" deste ditasse os novos preceitos do movimento artístico (in TELLES, 1983, p. 95-99); b) o cubo-futurista Vassíli Kamiênski, que foi mesmo um dos primeiros aviadores

Revista Texto Poético | ISSN: 1808-5385 | Vol. 19 (2o sem-2015) - p. 195 
Todos-os-Foras" (MELO NETO, 1994, p. 227), na inusitada expressão do poeta. Como um macro-objeto dinâmico, a ser percebido e interpretado com signos diversos, carregados de objetos ainda imediatos, o espaço fisisico se acha assim delimitado, tal como o tempo, que é o de um voo diurno, ambos reverberando na psique de um sujeito, a qual irá evidenciar-se, ao final da composição, num literal fechar de olhos.

Cinco partes arábicas tem o texto, dissemos. A aeronave e o passageiro poético, que nela viaja, efetuam vários movimentos circulares, em espiral, desde a decolagem do aeroporto de Ibura, em Pernambuco, estado natal do grande poeta, rumo a "Todos-os-Fora", ou seja, os vários exteriores do mesmo estado - e até do sujeito, que, ao fim, buscará retornar mentalmente ao interior de ambos, "para dentro" de si e do estado (CABRAL, 1994, p. 232). Giremos junto com eles, na atmosfera terrestre. Curiosamente, os círculos aéreos também são descritos por meio do recurso retórico denominado elipse, que suprime certas parcelas (ou signos) de um discurso.

Círculo inicial (PARTE 1), o da decolagem: "Se vem numa espiral / da coisa à sua memória. // $\mathrm{O}$ primeiro círculo é quando / o avião no campo do Ibura. / Quando tenso na pista / o salto ele calcula" (MELO NETO, 1994, p. 227: destaques nossos).

Já neste círculo o passageiro notará que a realidade, tal como vista do chão, irá modificando-se, quando observada de dentro do aparelho, sobretudo à medida que este elevar-se: "Está o Ibura onde

da Rússia, escreveu um poema ("Desafio"), em 1914, que se enquadra, com brilho, na categoria dos "aeropoemas" (in CAMPOS, CAMPOS, SCHNAIDERMAN, 2001, p. 101). 
coqueiros, / onde cajueiros, Guararapes ${ }^{45}$. / Contudo já parece / em vitrine a paisagem" (MELO NETO, 1994, p. 227: destaques nossos). Uma paisagem que deverá suavizar os seus aspectos mais duros (os seus objetos dinâmicos menos agradáveis): "O aeroporto onde o mar e mangues, / onde o mareiro e a maresia. / Mas ar condicionado, / mas enlatada brisa" (MELO NETO, 1994, p. 227: destaques nossos). Ainda: "De Pernambuco, no aeroporto, / a vista já pouco recolhe. / É o mesmo, recoberto, / porém, de celuloide. // Nos aeroportos sempre as coisas / se distanciam ou celofane. / No de Ibura até mesmo / a água doída, o mangue" (MELO NETO, 1994, p. 227-228: destaques nossos). Ora, conforme a composição ou a aeronave avança, observaremos que o seu ocupante não quer perder de vista pormenores do real como o mangue, não por gosto mórbido, obviamente, mas por enfoque crítico do mundo que conheceu (uma das bandeiras da poética de Cabral, um dos seus interpretantes com aparência de final, aliás). Ele os terá fora da sua visão, sim, porém, irá recuperá-los, não através dos globos oculares: pelos olhos da mente, digamos (e esperemos até a quinta parte do poema, para topar melhor com isto, quando a "memória" retornará, ou fará as coisas retornarem, recuperando objetos dinâmicos perdidos, sem deixar de produzir novos interpretantes).

Próximo círculo da nossa espiral (PARTE 2): "No segundo círculo, o avião / vai de gavião por sobre o campo. / A vista tenta dar / um último balanço" (MELO NETO, 1994, p. 228). O balanço é dado (feito), nas oito estrofes da segunda parte, através de "vidros lúcidos": o "ocre / que à tarde queima Olinda"; os "verdes do verde,

${ }^{45}$ Eis a primeira aparição da figura da elipse no poema: "Está o Ibura onde [se acham, se veem, etc.] coqueiros, / onde [se acham, se veem, etc.] cajueiros, [em] Guararapes".

Revista Texto Poético | ISSN: 1808-5385 | Vol. 19 (2o sem-2015) - p. 197 
submarinos" e - inesperada, criativamente - "sobremarinos" (um novo signo), que "dos dois lados da praia / estendem-se indistintos" (MELO NETO, 1994, p. 228: destaques nossos). Num autor como Cabral, bastante marcado pela visualidade (que, aliás, dela fez outra das bandeiras da sua poética $\left.{ }^{46}\right)$, tais detalhes cromáticos deveriam manifestar-se, induzindo o leitor a elaborar interpretantes dinâmicos sensoriais, recorrendo à gama de objetos imediatos que a sua mente já carrega, em confronto com a composição cabralina.

Neste círculo segundo, não deixa de aparecer uma sucessão de imagens cujas associações insólitas, engenhosas, "brilhantes", lembram outras tantas de um período estilístico que Cabral não apreciava: o barroco ${ }^{47}$. Vejamos: "eis os arrabaldes, dispostos / numa constelação casual; / [...] // e eis o Recife, sol de todo / o sistema solar da planície: / daqui é uma estrela / ou uma aranha, o Recife, // se estrela, que estende seus dedos, / / se aranha, que estende sua teia" (MELO NETO, 1994, p. 228-229: destaques nossos). Estrela e aranha, Recife "estende sua cidade / por entre a lama negra" (MELO NETO, 1994, p. 229: destaques nossos). Sabemos

${ }^{46}$ Não resistimos a citar uma passagem de $O$ cão sem plumas, na qual a bandeira se torna uma imagem inusitadamente associada a outras: "(Como o rio era um cachorro, / o mar podia ser uma bandeira / azul e branca / desdobrada / no extremo do curso / - ou do mastro - / do rio. // Uma bandeira / que tivesse dentes: / que o mar está sempre / com seus dentes e seu sabão / roendo suas praias. // Uma bandeira / que tivesse dentes: / como um poeta puro / polindo esqueletos, / como um roedor puro, / um polícia puro / elaborando esqueletos, / o mar, / com afã, / está sempre outra vez lavando / seu puro esqueleto de areia [...])" (CABRAL, 1994, 111-112).

${ }^{47}$ Ao fim e ao cabo, o barroquismo de que a poesia cabralina se afasta é o gongórico ou "cultista", não o quevediano ou "conceptista". Uma das marcas próprias da sua lírica é o jogo intelectual, o desdobramento inusitado do fio de ideias, algo típico do quevedismo (e da poesia "metafísica" inglesa) - e de Góngora, não poucas vezes.

Revista Texto Poético | ISSN: 1808-5385 | Vol. 19 (2o sem-2015) - p. 198 
bem: o passageiro "De um avião" não deseja perder de vista coisas como a "lama" do seu estado. Ele, todavia, os vê fugir aos poucos do seu campo visual, como a última (e parentética) quadra da segunda parte mostra: "(Já a distância sobre seus vidros / passou outra mão de verniz: / ainda enxergo o homem, / não mais sua cicatriz)" (MELO NETO, 1994, p. 229: destaques nossos). A "cicatriz" é metáfora que vale pelos dados negativos da realidade ${ }^{48}$ - e aqui ela aparece associada a um signo que faz a sua primeira irrupção no texto: o "homem". Este retornará - e, em princípio, antropocentricamente.

Terceiro círculo espiralado (PARTE 3): intensifica-se aqui a rarefação do real mais difícil. Ei-la: "O avião agora mais alto / se eleva ao círculo terceiro, / folh a de papel de seda / velando agora o texto" (MELO NETO, 1994, p. 229: destaques nossos).

Interessante o fio discursivo que se vale de um encadeamento metafórico ligado à área textual, linguística (ou de semiose verbal), por sua vez associada aqui a um purismo de representação que o nosso passageiro recusa: "A paisagem, ainda a mesma, / parece agora noutra língua: / numa língua mais culta, / sem vozes de cozinha. // Para língua mais diplomática / a paisagem foi traduzida / [...] // onde a água morta do alagado / passa a chamar-se de marema / e nada tem da gosma, / morna e carnal, de lesma" (MELO NETO, 1994, p. 229-230: destaques nossos). Um habitante do solo reaparece, mas apenas por meio de menção verbal, pois sumira de vista, em benefício do purismo referido: "Se daqui se visse seu homem, / homem mesmo pareceria: / mas ele é o primeiro / que a distância eneblina // para não corromper, decerto, / o texto

${ }^{48}$ A cicatriz é um dado pós-traumático: um signo que indica a ocorrência anterior de um trauma.

Revista Texto Poético | ISSN: 1808-5385 | Vol. 19 (2o sem-2015) - p. 199 
sempre mais idílico / que o avião dá a ler / de um a outro círculo" (MELO NETO, 1994, p. 230: destaques nossos, inclusive em mais um novo signo proposto pelo autor: "eneblina").

Além do campo metafórico linguístico-textual acima (ou prática de metalinguagem, uma terceira bandeira da lírica de Cabral), nesta PARTE 3 comparecem termos ligados às artes plásticas e visuais, áreas de semiose não apenas verbal (o que retoma o cromatismo da parte dois): "Uma paisagem mais serena, / mais estruturada, se avista: / todas, de um avião, / são de mapa ou cubistas. // A paisagem [...] / onde as casas são brancas / e o branco, fresca tinta; // onde as estradas são geométricas / e a terra não precisa limpa" (MELO NETO, 1994, p. 229: destaques nossos).

Quarto e quinto círculos (PARTE 4): altura mais elevada, maior diluição da dura realidade do chão - ou dos seus objetos dinâmicos mais "intratáveis".

Retorna o campo de referências dinamicamente interpretadas com signos plástico-visuais: "Primeiro, a distância se põe / a fazer mais simples as linhas; / os recifes e a praia / com régua pura risca. // A cidade toda é quadrada / em paginação de jornal / [...]. // Depois, a distância suprime / por completo todas as linhas: / restam somente cores / justapostas sem fímbria: // o amarelo da cana verde, / o vermelho do ocre amarelo, / verde do mar azul, / roxo do chão vermelho" (MELO NETO, 1994, p. 230-231: destaques nossos). Ainda: "Até que num círculo mais alto / essas mesmas cores reduz: / à sua chama interna, / comum, à sua luz, // que nas cores de Pernambuco / é uma chama lavada e alegre, / [...] // até que enfim todas as cores / das coisas que são Pernambuco / fundem-se todas nessa / luz de diamante puro" (MELO NETO, 1994, p. 231: destaques nossos).

Revista Texto Poético | ISSN: 1808-5385 | Vol. 19 (2o sem-2015) - p. 200 
A menção a algo como o "diamante", no texto, outra vez faz recordar as metáforas esplendorosas, suntuosas, do barroco. Aguardemos, todavia, a sua reaparição - e $\operatorname{logo}$ o seu desaparecimento - e o seu reaparecer - e o seu novo sumiço (tudo isto na PARTE 5).

Novidade desta PARTE 4: ao que parece, houve dois movimentos circulares. O quarto fora: "Num círculo ainda mais alto / o avião aponta pelo mar". O quinto: "Até que num círculo mais alto / essas mesmas cores [a distância] reduz" (MELO NETO, 1994, p. 230 e 231, respectivamente: destaques nossos).

Sexto círculo e outros mais, em quantidade indefinida (PARTE 5): "Penetra por fim o avião / pelos círculos derradeiros. / A ponta do diamante / perdeu-se por inteiro. // Até mesmo a luz do diamante / findou cegando-se no longe. / Sua ponta já rombuda / tanto chumbo não rompe" (MELO NETO, 1994, p. 231: destaques nossos).

Reaparecendo e logo desaparecendo, o diamante (a luz "pura" das alturas) cede ao que pode ser tido como um oposto seu, vale dizer, uma espécie de céu plúmbeo: "Tanto chumbo como o que cobre $^{49}$ / todas as coisas aqui fora. / Já agora Pernambuco / é o que coube a memória" (MELO NETO, 1994, p. 231: destaques nossos). A difícil realidade de Pernambuco (metonímia-parte de qualquer realidade difícil do mundo-todo) desapareceu do horizonte vislumbrado pelas janelas do avião, voando este cada vez mais alto.

49 "Cobre", aqui: sem dúvida, o verbo cobrir na terceira pessoa do singular do presente do indicativo, mas também, por equívoco (paronomásia), o substantivo cobre. Outra engenhosidade verbal digna do barroquismo (aliás, da espécie que a modernidade apreciou bastante). Também é paronomástico o jogo entre "COBrE" e "COuBE", na mesma estrofe.

Revista Texto Poético | ISSN: 1808-5385 | Vol. 19 (2o sem-2015) - p. 201 
Apenas algo pode recuperar o macro-objeto dinâmico (sensorial e social) que foi perdido: aliás, não exatamente algo, mas o sujeito, a subjetividade do passageiro. A visão, o objetivismo, a sensorialidade, a atenção às coisas - tudo isto, que, em termos de interpretantes dinâmicos críticos, é muito associado à poética de Cabral, de nada serve aqui, sem a decisão tomada pelo eu lírico, de reagir de modo - insistamos - subjetivo: "Já para encontrar Pernambuco / o melhor é fechar os olhos / e buscar na lembrança / o diamante ilusório" (MELO NETO, 1994, p. 231: destaques nossos). Ilusório é também supor que o passageiro quer, de fato, o "diamante": ele almeja o que está "abaixo" deste - e não esqueçamos que a pedra preciosa é, no texto, metáfora (ou interpretante dinâmico) da luminosidade das alturas (como o poeta destaca), não literalmente um mineral. $\mathrm{Na}$ verdade, o passageiro deseja voltar ao solo, ou melhor, tornar a ver o que deixou de enxergar no campo celeste. A jornada "diamante abaixo" - digamos assim - é efetuada em, ao menos, três etapas.

A primeira: "É buscar aquele diamante / em que o vi se cristalizar, / que rompeu a distância / com dureza solar" (MELO NETO, 1994, p. 231: destaques nossos).

A segunda: "refazer aquele diamante / que vi apurar-se cá de cima, / que de lama e de sol / compôs luz incisiva" (MELO NETO, 1994, p. 232: destaques nossos).

A terceira: "desfazer aquele diamante / a partir do que o fez por último, / de fora para dentro, / da casca para o fundo" (MELO NETO, 1994, p. 232: destaques nossos).

Sabemos não ser deveras o "diamante" o que busca o passageiro "De um avião". Ele deseja ir "da casca para o fundo, // até aquilo que, por primeiro / se apagar, ficou mais oculto: / o

Revista Texto Poético | ISSN: 1808-5385 | Vol. 19 (2o sem-2015) - p. 202 
homem, que é o núcleo / do núcleo de seu núcleo" (MELO NETO, 1994, p. 232: destaques nossos). Assim, muito subjetivamente (por meio da "lembrança", da "memória" já mencionada no quarto verso do conjunto), o sujeito individual da composição lírico-descritiva "De um avião" encontra o sujeito humano geral, centrado em si, autocentrado (como o metaforismo triádico do "núcleo" revela). Ao menos nos limites do mundo elaborado pelo texto, tudo isto (que podemos resumir como "homem-núcleo") adquire ares de interpretante final.

Desembarquemos agora no campo da física, finalmente.

$\mathrm{Na}$ antiguidade, Aristarco de Samos tirara a Terra, portanto, o homem, do centro físico do universo, descobrindo que o planeta girava em torno do Sol, não o contrário. O seu achado inteligentíssimo, entretanto, não encontrou receptividade por vários séculos, ofuscado pelo modelo geocêntrico aristotélico-ptolomaico. Ciente de Aristarco, o cônego e físico Copérnico relançaria, no século XVI, a ideia do seu velho predecessor. Sabemos que, além de Galileu e Kepler, um dos sucessores do próprio Copérnico chamouse Isaac Newton. Dos diversos legados newtonianos à física, um deles foi o de que o espaço e o tempo eram absolutos, ou seja, os mesmos para quaisquer observadores, pouco importando os referenciais (as situações) a partir dos (das) quais as pessoas os medissem. Frente a tais espaço e tempo absolutos, o desfecho da composição de Cabral acaba por retomar certo antropocentrismo, certo humanismo, abalado por Copérnico ao fim do Renascimento e, como veremos, por Freud modernamente (1916-1917): "o homem, que é o núcleo / do núcleo de seu núcleo" (MELO NETO, 1994, p. 232), como já citamos. Algo aqui apenas "poético", "bonito" todavia, inócuo, em termos do lugar (supostamente) verdadeiro, 
insignificante, que ocupamos no real. Toda esta perspectiva pode ser considerada como um primeiro grande interpretante no mínimo dinâmico (situado nos limites da mecânica newtoniana) para os signos do poema cabralino, que remetem a objetos dinâmicos bastante enraizados na realidade brasileira (ou pernambucana). Mas... e se o "homem", como qualquer objeto mais definido, puder estar deveras não no centro (geográfico) do cosmo, mas num dos seus múltiplos centros (luminosos)? Tudo mudará de figura (ou de interpretante) - inclusive o desfecho do poema cabralino. Para isto, todavia, precisamos abandonar o absolutismo do espaço e do tempo, até mesmo a suposição de que tais entidades são independentes, como pareceram ser - de modo tão avassalador que atuavam como interpretantes finais, na prática (ou semiose) da física que chega ao século XIX, e até fora dela. Voltemos a 1905 e 1907, aos revolucionários dias de Einstein e do seu professor de matemática Herman Minkowski, quando a teoria da relatividade restrita veio ao mundo, alterando as noções de realidade física, de tempo e espaço, herdeiras que eram da mecânica newtoniana.

Tivemos a satisfação de percorrer os versos de Cabral. Tenhamos a paciência de entrar um pouco mais na área da física, de início levando em conta uma referência freudiana a Copérnico, a qual veio a gerar o que, mais tarde, ficaria célebre como "descentramento" (interpretante dinâmico que passou a funcionar como final, em certos setores de Humanidades). Para dar conta disto, precisaremos deixar a composição cabralina no ponto em que chegamos, "estacionada" ali por cerca de seis páginas, esperando a hora de decolar com ela de novo, mais à frente. Iremos obter o segundo grande interpretante no mínimo dinâmico para o mesmo poema (já não mais localizado na área newtoniana da física). 


\section{Descentramento e antissubjetivismo como casos de um multicentramento mais amplo, onde - mais do que espaço - há espaço-tempo para o sujeito, afinal}

Freud não forjou o signo "descentramento", mas, no começo do século XX, ele foi o grande deflagrador do que a noção passou a significar, sobretudo através de uma conferência de Derrida dos anos 1960, onde o termo aparece de modo explícito. O Freud que importa agora é o de dois textos de 1916-1917, a saber, a XVIII das Conferências introdutórias sobre psicanálise ("Fixação em traumas - O inconsciente") e um artigo estampado no periódico húngaro Nuygat ("Uma dificuldade no caminho da psicanálise") 50 .

Com rapidez, vejamos o que, a partir destes dois escritos, ganhou celebridade: os três golpes sofridos pelo ser humano em seu narcisismo, desferidos por Copérnico (golpe cosmológico), Darwin (golpe biológico) e o próprio Freud (golpe psicanalítico). Com o seu (neo)heliocentrismo, Copérnico arrancou os homens de um suposto centro físico do universo. Com a sua teoria da evolução das espécies, Darwin retirou os homens do centro do reino animal. Com a sua psicanálise, Freud tirou os homens do centro das suas mentes (obrigando o ego humano a reconhecer a ação do inconsciente, que ele de fato não parece comandar).

Em linhas muito gerais, esta foi uma das heranças de Freud, que seria retomada no âmbito do estruturalismo francês, tornandose lugar comum nos chamados pós-estruturalismo ou pós-

${ }^{50}$ Freud, 2006a, 281-292. O artigo referido encontra-se em Freud, 2006b, 147-153.

Revista Texto Poético | ISSN: 1808-5385 | Vol. 19 (2o sem-2015) - p. 205 
modernismo. O papel de Jacques Derrida em tudo isto foi bastante grande.

"A estrutura, o signo e o jogo no discurso das ciências humanas" foi uma brilhante conferência do pensador francoargelino proferida em Baltimore, em 1966, num evento no qual Lacan também tomou parte. Nos parágrafos do texto derridiano, possivelmente o vocábulo "descentramento" apareça pela primeira vez, no campo filosófico.

Um Glossário de Derrida, elaborado por Silviano Santiago e os seus pós-graduandos dos anos 1970, ajuda-nos a retomar, sinteticamente, a abordagem da temática em questão, no pensamento do filósofo (SANTIAGO, 1976). Aqui, o descentramento é uma modalidade de interpretação ou "leitura intertextual", que se opõe "aos conceitos clássicos de estrutura centrada, origem e presença"; tal "atividade interpretativa" pratica-se com a eliminação de "qualquer referência a um centro, a um sujeito" - em benefício de uma "leitura desconstrutora" (ou "leitura descentrada"), orientada pela necessidade de "anulação do centro como lugar fixo e imóvel" (SANTIAGO, 1976, p. 18: destaque nosso) ${ }^{51}$.

$\mathrm{O}$ artigo-conferência de Derrida retoma, em primeiro lugar, um trio: Nietzsche, Freud e Heidegger. Estes seriam os autores que iniciaram a tarefa de descentramento que o filósofo da

${ }^{51}$ Nesta e nas próximas citações, note-se um afastamento da noção de sujeito, algo que, em geral, o pensamento estruturalista partilhou, apesar das diferenças dos seus protagonistas. (Nas linhas e entrelinhas dos termos citados, a problemática da intertextualidade explica muitas coisas: a "prática interpretativa" será feita de signos que, num discurso, provenham de outro(s) discursivo(s), portanto, sem "referência a um centro" - o que, supomos, não autoriza o descarte do(s) sujeito(s), necessariamente envolvido(s) em qualquer processo intertextual.)

Revista Texto Poético | ISSN: 1808-5385 | Vol. 19 (2o sem-2015) - p. 206 
desconstrução, então, explicitava: a "crítica nietzschiana da metafísica, dos conceitos de ser e de verdade [...]; a crítica freudiana da presença a si, [...] da consciência do sujeito, da identidade a si, da proximidade ou da propriedade de si; e, mais radicalmente, a destruição heideggeriana da metafísica, da onto-teologia, da determinação do ser como presença" (DERRIDA, 1968, 104: destaque nosso). Um quarto autor virá fortalecer ainda mais os argumentos derridianos de 1966: Claude Lévi-Strauss.

Nos escritos do antropólogo a respeito dos mitos, Derrida nota que, ao lado de uma visão "clássica" da concepção de estrutura, surge uma concepção nova, a do estruturalismo daqueles anos (depois incorporada pelos que se posicionarão como pósestruturalistas, repetimos). Qual? A seguinte: na "estrutura clássica" haveria sempre um centro; a história se encarregaria de substituir tal centro por outros ("essência, existência, substância, sujeito" e, ainda, "transcendentalidade, consciência, Deus, homem, etc.": DERRIDA, 1968, p. 103: destaque nosso). Lugar privilegiado, o do centro, que furtar-se-ia, assim, ao jogo combinatório e à permuta de elementos, característico da sua estrutura maior: dessa maneira, o centro escaparia à estruturalidade que, em cada situação, comandasse.

Após Nietzsche, Freud e Heidegger, o que o estruturalismo lévistraussiano, a partir do estudo dos mitos, invalidava, segundo Derrida, era a própria necessidade de existência de existência de centro. Ora, o notório interesse de tal estruturalismo pela problemática dos signos linguísticos, sobretudo devido ao impacto da reflexão de Ferdinand de Saussure a propósito dela, foi um dos fatores poderosos para tal questionamento. Pensemos num signo, numa palavra: estando esta no lugar de alguma coisa, concreta ou abstrata, vemos que não é ela precisamente uma presença, um centro 
do que quer que haja. Simplesmente, ela substitui algo, de um modo ou de outro, algo ausente. ${ }^{52}$ (Ela pode ser combinada e permutada de múltiplas maneiras.)

Com o passar das décadas, a reflexão que acima resumimos se tornou "clássica", por seu lado (talvez "neoclássica"), parecendo-nos merecedora de tal celebridade. De modo nenhum pretendemos invalidar a sua relevância. É inegável que vários fatores do mundo não parecem mesmo carregar centros: a história dos homens, os seus mitos, as línguas que eles falam, os demais sistemas de signos, os signos que não se organizam em sistemas, as diversas culturas, a própria vida em geral... - e outros itens que possam aumentar esta lista. Perguntemos, contudo: a lista não terá um limite, por mais extensa e aberta que seja? Para defender a ideia desse limite, comecemos por voltar ao título da reflexão de Derrida: "A estrutura, o signo e o jogo no discurso das ciências humanas". Sim, ciências humanas, humanidades, onde o estruturalismo atuou, onde o pósmodernismo continua atuando, predominantemente. Não é fácil, todavia, conduzir a noção de descentramento, por mais válida que ela se revele aqui, para o terreno das ciências naturais, principalmente para o que foi desbravado por Einstein, a partir de 1905. Tentemos, porém.

${ }^{52}$ Esta coisa ausente de fato não comanda o discurso que dela fale. Este é o ponto de vista costumeiro (e correto) da reflexão estruturalista, que se difundiu, sobretudo, a partir dos anos 1960. Um modo de pensar que the antecedeu, mas apenas ecoou pelo mundo intelectual, bem lentamente, a partir da década de 1970, como o de Charles Sanders Peirce, tem outro enfoque. A "coisa ausente" seria o "objeto dinâmico" peirciano, que, decerto, também "não comanda" o encadeamento discursivo (ou semiótico), mas, como Peirce percebeu, o motiva. Na semiótica (triádica) do pensador norteamericano, "[...] o signo determina o interpretante, mas ele o determina como uma determinação do objeto" (SANTAELLA, 1995, p. 38. "Determinar" é algo diverso de "comandar".) Interpretante, certamente, não é sinônimo de sujeito, mas qualquer sujeito exercerá a função de interpretante.

Revista Texto Poético | ISSN: 1808-5385 | Vol. 19 (2o sem-2015) - p. 208 
Um fator decisivo para a prática do descentramento (ainda nomeado como "golpe" por Freud) era originário da física: o (neo)heliocentrismo de Copérnico. Parece-nos urgente enriquecer o debate com uma versão mais acurada da física, muito mal divulgada nos anos em que Freud escrevia (1916-1917): a já mencionada teoria da relatividade restrita. Agora, desenhemos o chamado cone de luz relativístico, sem receio das suas implicações estranhas:

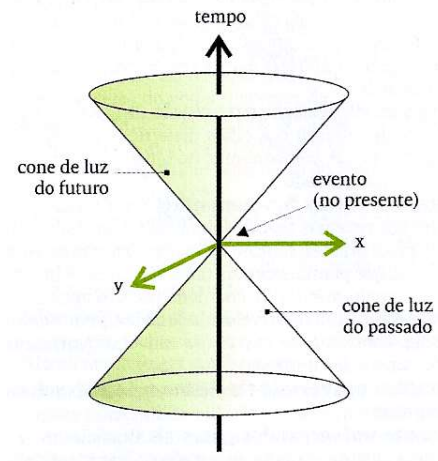

Cone de luz do espaço-tempo (Figura 1)

Observamos aqui um diagrama (no caso, um complexo sígnico gráfico-linguístico, extraído de RODITI, 2005, p. 49) que representa parte da realidade física, na qual se insere tudo que se passa em grandes dimensões, como as da rotação da Terra ao redor do Sol e as da leitura de textos. Claro, tal representação é simplificadora, pois, numa superfície plana, busca dar conta das três dimensões do espaço e da dimensão de tempo, de coordenadas não independentes umas das outras. Tal diagrama resulta, logicamente, da teoria da relatividade especial ou restrita, proposta em 1905 por Albert 
Einstein e depois (1907) interpretada por Hermann Minkowski no sentido de um continuum espaço-temporal, sem igual no corpus da física newtoniana, limitada que se achava esta a uma versão tridimensional da realidade, um "teatro" onde pura e simplesmente fluiria o tempo, sempre do mesmo modo para todos. ${ }^{53}$

Com os nossos órgãos sensoriais, não podemos, entretanto, visualizar uma autêntica realidade de quatro dimensões, pois enxergamos tão só três dimensões. Lancemos mão, pois, de uma simplificação óptica: as três dimensões espaciais (comprimento, largura, altura) sejam representadas por apenas dois eixos dispostos na horizontal $(X$ e $Y)$; o tempo seja simbolizado por um eixo vertical. No diagrama citado mais acima aparecem, de fato, dois cones, não um, unidos pelos seus vértices: o de cima remete aos acontecimentos do futuro; o ponto em que os seus vértices se interceptam é o presente, onde se encontra o observador; o cone da parte inferior da figura remete aos eventos do passado.

$\mathrm{O}$ ângulo de inclinação de $45^{\circ}$ do cone decorre do detalhe de apenas a luz viajar cerca de 300.000 quilômetros por segundo no vácuo. Este ângulo, aliás, merece explicação melhor, o que tentaremos fazer, recorrendo a Kitty Fergusson. Diz ela: "Se algo se move três jardas no espaço e quatro no tempo, está se movendo a três quartos da velocidade da luz [...]. Se algo se move quatro jardas no espaço e três no tempo, está acima da velocidade da luz, o que não é permitido" (FERGUSSON, 2012, p. 186). Indo adiante no raciocínio: tendo as três jardas como referência, e sabendo que apenas à luz é facultado viajar as mesmas três jardas tanto no espaço

${ }^{53}$ Uma explicação da interpretação de Minkowski da relatividade restrita encontra-se em EINSTEIN, 2009, 76-78, 101.

Revista Texto Poético | ISSN: 1808-5385 | Vol. 19 (2o sem-2015) - p. 210 
(eixos $X$ e $Y$ do nosso diagrama) quanto no tempo (eixo vertical do mesmo diagrama), obtemos o ângulo de $45^{\circ}$.

Continuemos.

A teoria da relatividade restrita implica (ou impõe como interpretante com aparência de final) que a velocidade da luz seja absoluta (invariante) para todos os observadores e o mesmo ângulo vale como referência para todos os cones luminosos ou eventos envolvendo o presente, o passado e o futuro deste ou daquele indivíduo no cosmo. (Neste caso, na teoria einsteiniana, o seu papel é semelhante ao do espaço e do tempo na teoria newtoniana: ela é um absoluto.)

Vejamos o caso de uma informação que provenha do interior do cone de luz do passado: ela atingirá o observador situado no ponto em que os vértices dos dois cones se encontram - o presente. Observemos agora o caso de uma informação que proceda do exterior do cone luminoso do passado: ela apenas atingirá o observador quando ele estiver colocado num ponto que se situe além dos vértices onde os dois cones se tocam: um lugar no futuro, para onde ele se deslocará.

De tudo isto resulta algo estranho, vale dizer, que o universo nem é ptolomaicamente "centrado" nem copernicamente "descentrado" 54 . Quando topamos com o ponto de vista relativístico (einstein-minkowskiano), descobrimos um surpreendente modelo multicentrado para os observadores do cosmo, humanos ou não humanos. Toda esta estranheza decorre de as descobertas da teoria da relatividade restrita (e as da geral ainda mais) serem o que os

${ }^{54}$ Bem entendido, "descentrado" em relação à Terra, pois, como se sabe, Copérnico recentrou o cosmo em torno do Sol (heliocentrismo).

Revista Texto Poético | ISSN: 1808-5385 | Vol. 19 (2o sem-2015) - p. 211 
físicos rotulam como contraintuitivas, ou seja, temos dificuldade de, com a mente, visualizar os seus modelos (como a quadridimensionalidade espaço-temporal), condicionados que estamos pelo meio-ambiente circundante. Resumo da ópera (pósnewtoniana): somos "agora" (ou desde 1905-1907) levados a pensar num universo quadridimensional multicentrado, algo que nos centra a todo o momento - um cosmo com excesso de centros... ${ }^{55}$ Como toda a série de itens macrocósmicos concebíveis deverá estar contida no espaço-tempo, também se localizará no duplo cone de luz relativístico ${ }^{56}$.

Achamo-nos, portanto, na obrigação de admitir algo: o descentramento derridiano é um caso do multicentramento resultante da teorização de Einstein-Minkowski. E este abarca ainda a noção de deslocamento, porque o duplo cone já se desloca ininterruptamente para o futuro, para o devir, tendo a velocidade da luz no vácuo como o limite superior para a transmissão de informações acerca do se passa (nós agora incluídos) no seu interior: não há nada "fixo e imóvel" aqui. ${ }^{57}$

${ }^{55}$ A concepção de multicentramento não pode ser confundida com qualquer etnocentrismo. Nela, óbvio que a ideia de um centro é inconcebível.

${ }^{56}$ Uma sutileza impõe-se aqui: nos domínios atômico e subatômico, tratados pela física quântica, o espaço-tempo pode ter a sua validade diminuída. Um físico disse claramente: "O espaço e o tempo [...] são dois dos conceitos clássicos mais fundamentais, mas de acordo com a mecânica quântica são secundários. Os emaranhamentos [quânticos] são primários. [...] Devemos explicar o espaço e o tempo como algo que emerge de uma física sem espaço ou tempo" (VEDRAL, 2011, 35). Falaremos do incrível emaranhamento quântico adiante.

${ }^{57}$ Por vezes de modo empobrecido, a reflexão de Derrida é assimilada ao pós-modernismo (termo que não aparece, ou só muito esporadicamente, na extensíssima obra do filósofo). Pois bem: tal reflexão encontra aqui, numa teoria científica moderna como a relatividade restrita, um limite de 
O parágrafo acima é o que mais importa para o nosso retorno ao poema de Cabral, mas não devemos deixar passar a oportunidade de recordar uma consequência inusitada da relatividade restrita.

Dependendo da situação em que se encontrem os observadores, o contínuo do espaço-tempo irá apresentar-se para eles de modos diferentes. Se uma pessoa A se acha num veículo que ganha velocidades altíssimas, e outra pessoa B não, experimentará um tempo (objetivo) que se irá dilatar-se, com o espaço contraindo-se, em torno de si - o que equivale a dizer que o sujeito A envelhecerá mais lentamente do que o $\mathrm{B}$, mesmo que ambos sejam gêmeos. $\mathrm{O}$ (duplo) cone de luz relativístico imporá condições temporais e espaciais diferentes aos dois, baseado na mesmíssima velocidade da luz, o que indica que a teoria da relatividade restrita não é, afinal, mais um relativismo cultural... - bem ao contrário! Ao que parece, nada no passado científico e filosófico da humanidade, de índole materialista ou não, fazia prever esta "plasticidade" (ou relativismo) do espaço e do tempo - agora concebível como um contínuo espaçotemporal -, mas frisemos: isto nada tem a ver com o que, costumeiramente, se chama subjetivismo (voluntarismo) - e, assim, qualquer materialismo (ou suposição de que a realidade não é mera criação da mente do sujeito) pode (e deve) incorporar o legado einstein-minkowskiano ao seu arcabouço, à sua visão de mundo, sob pena de ficar defasado em relação ao capitalismo, que, do ponto de vista tecnológico, lida com tais coisas com a maior desenvoltura, como o mostra o uso do sistema GPS (Sistema de Posição de Satélites), o qual leva em conta a relatividade restrita, para funcionar...

aplicabilidade - o que se coaduna com o trajeto derridiano, que não viu necessidade de desconstruir as ciências naturais, que saibamos.

Revista Texto Poético | ISSN: 1808-5385 | Vol. 19 (2o sem-2015) - p. 213 
Voltemos à aeronave de Cabral.

Subjetivamente, ao "fechar os olhos", o passageiro "De um avião", por meio da "memória", quer reencontrar "aquilo que, por primeiro / se apagar, ficou mais oculto: / o homem, que é o núcleo / do núcleo de seu núcleo" (CABRAL, 1994, p. 232). Ora, pelo que acabamos de examinar em termos de teoria da relatividade, mesmo a subjetividade em geral, quando manifestar-se através de indivíduos específicos, irá fazê-lo dentro de um (duplo) cone de luz relativístico, este sim um palco, móvel, dinâmico, extremamente "plástico", com distorções do espaço-tempo: agora, espaço e tempo não se mostram absolutos, não sendo, portanto, sempre os mesmos, ou tendo os mesmos comportamentos, em todas as circunstâncias.

Não perdendo de vista o poema de Cabral: como segundo grande interpretante ao menos dinâmico extraído das estrofes que formam "De um avião", para além do antropocentrismo ou humanismo, podemos dizer que, sim, o homem - ou a humanidade - será o "núcleo / do núcleo do seu núcleo", porque sempre estará no centro (no "núcleo") de um (duplo) cone de luz relativístico, em qualquer ponto do universo em que tal humanidade - ou homemafinal se localize. O ser humano ou não importa que outro ser do cosmo, ou mesmo um ser não vivo. Ora, ao invés de banalizar o nosso lugar no real, isto nos valoriza (de um modo não Kitsch), como valoriza tudo o mais (de um jeito não "baratamente" consolador das demais coisas, com humano paternalismo). Deveras, uma pedra também está no centro de um (duplo) cone de luz relativístico. Respeitemos as pedras, portanto (até em respeito a Cabral, que, desde o início da sua obra, com Pedra do sono, as tomou como um dos seus símbolos fundamentais). Respeitemos também as nossas psiques, o fato de que, objetivamente, podemos, às vezes, "fechar os 
olhos" para, por meio do fator memória da nossa subjetividade, retomar algo (ou muito) do cone de luz do passado - no caso do poema: objetos dinâmicos como o mangue, com "água doída", "lama negra", "gosma, / morna e carnal, / de lesma", enfim, o "homem" e sua "cicatriz". Se levarmos em conta algumas ciências naturais, como o campo da física moderna, entenderemos o motivo de um cosmólogo (Joel R. Primack) e uma escritora da área de ciências (Nancy Elle Abrams) escreverem algo como: "O centro do nosso universo visível [cone de luz relativístico] não é um lugar, mas uma colaboração cósmica de espaço, tempo, luz e consciência" (PRIMACK; ABRAMS, 2008, p. 152). Óbvio, se não tivéssemos consciência, vale dizer, psique (que inclui o inconsciente freudiano, que tem recebido confirmação científica desde o fim dos anos 1980: cf. CALLEGARO, 2011, passim), vale dizer ainda, se não fôssemos sujeitos com a possibilidade de "fechar os olhos", se, numa dada situação, vigêssemos apenas como pedras no meio de um caminho, a frase de Primack e Abrams iria requerer uma alteração. Ficaria assim, em (séria) lógica relativística: "O centro do nosso universo visível [cone de luz relativístico] não é um lugar, mas uma colaboração cósmica de espaço, tempo, luz e pedrinhas" que ali estejam, num presente qualquer, recebendo as informações do cone de luz do passado, enquanto se deslocam para o cone de luz de futuro. Troquemos as consciências (psiques) que somos e as pedrinhas que acabamos de considerar por uma letra: um X, por exemplo. Eis uma formulação geral, supomos que científica, para a mesma frase: "O centro do nosso universo visível [cone de luz relativístico] não é um lugar, mas uma colaboração cósmica de espaço, tempo, luz e X”.

Revista Texto Poético | ISSN: 1808-5385 | Vol. 19 (2o sem-2015) - p. 215 
Ao "fechar os olhos", avançando fisicamente para o futuro, o sujeito "De um avião" empreendeu uma jornada mental ao passado, mais precisamente, às informações do cone de luz do pretérito, claro que gravadas na sua memória: ao sempre referido mangue, com "água doída", à "lama negra", "gosma, / morna e carnal, / de lesma", enfim, ao "homem" e sua "cicatriz", como vimos. Sendo tudo isto, sem dúvida, subjetivo, até mesmo prova de um hiper-subjetivismo ou voluntarismo considerável, nem assim deixa de inserir-se numa macro-objetividade maior, implicada na teoria da relatividade restrita, a qual, em termos de grandes dimensões das coisas, só tem a the superar a relatividade geral, de autoria do mesmo sujeito humano chamado Einstein. Com a ciência deste e com a lírica de Cabral, entre muitas outras coisas, podemos perceber que a nossa atividade psíquica não é um dado a mais, "solto" no planeta, um "fragmento" irrelevante, "voando" à toa no universo.

\section{Para além da aeronave de Cabral}

Agora, na "cabeça" do terceiro milênio, caso tomemos o calendário cristão como referência, nesta segunda década de 2000, é desejável que, articulando a nossa situação ao que Einstein e Minkowski descobriram em 1905 e 1907, percebamos algo que a composição cabralina não contém - ou algo que ela contém apenas pela metade, por assim dizer.

Em "De um avião", o sujeito rumou fisicamente para o futuro, como sempre fazemos todos; mentalmente, por meio da memória, ele retornou ao passado, conforme qualquer um de nós também pode fazer. O futuro foi o "diamante", metáfora para os efeitos da luz em regiões mais elevadas da atmosfera terrestre, a um 
ponto tal que o próprio "diamante" acaba "cegando-se", num "chumbo" (em "alquimia invertida", digamos) onde a luminosidade se perdeu: "Sua ponta [do diamante] já rombuda / tanto chumbo não rompe" (CABRAL, 1994, p. 231). O passado seria o retorno subjetivo a Pernambuco, do qual partira o sujeito, e, mais do que ao seu estado natal, uma volta ao "homem", ao "núcleo" três vezes proclamado.

Tentamos mostrar o quanto, para além de qualquer mero antropocentrismo, tal "nuclearidade" se revela consistente com a relatividade restrita. Um detalhe importante não devemos deixar como que perdido no ar, todavia, sem que isto implique um julgamento conceitual (ou estético) da instigante composição cabralina. Qual? Ora, ela se decide por valorizar apenas uma das duas parcelas da realidade mais ampla narrada no poema, realidade que o sujeito experimentou, em primeiro lugar, em movimento físico ascendente, em círculos espiralados cada vez mais altos; em segundo, em movimento descendente puramente psíquico, fechando os olhos para a paisagem ao seu redor, em regresso subjetivo ao solo onde o "homem" e a sua "cicatriz" ficaram. O primeiro movimento se dá, progressivamente, para "fora", para "Todos-os-Fora" de Pernambuco, tal como é antecipado na estrofe de abertura do texto. $\mathrm{O}$ segundo ocorre, regressivamente, "de fora para dentro, / da casca para o fundo, // até aquilo que [...] / [...] ficou mais oculto: / o homem" (CABRAL, 1994, p. 232: destaques nossos). No primeiro caso, predominam o "diamante" (metáfora da luz) e o "chumbo" (metáfora de uma visão opaca da paisagem celeste); no segundo, o "fundo" e o "núcleo" prevalecem, simbolizando a humanidade sofrida. Estes últimos, com clareza, merecem a preferência do autor, ou do seu eu lírico, a darmos crédito ao que vem escrito em "De um avião". 
Como leitores de Cabral, aqui interpretado em chave einsteinminkowskiana, temos o direito, contudo, de frisar que as duas modalidades do real descritas no poema se revelam, afinal, válidas, explicáveis que são por meio do (duplo) cone de luz relativístico. O "diamante" e o "chumbo" valem por efeitos literalmente luminosos, ligados ao limite da velocidade da luz no vácuo; fechar os olhos para a luz circundante em torno também valem assim, pois, com tal decisão, o sujeito se concentra na sua própria atividade mental, associada esta a ondas cerebrais de natureza por igual eletromagnética, ou seja, luminífera. ${ }^{58}$ Mesmo que ignoremos este último pormenor, julgando-o cientificista em excesso (desnecessário para a interpretação do texto), não precisamos desprezar o fato de que a decisão subjetiva e o ato de fechar os olhos acontecem apenas em processos contextualizáveis no (duplo) cone aludido, tenhamos ou não consciência disto.

Parece-nos que o incrível dado científico desvelado por Einstein e o seu ex-professor Minkowski, em 1905 e 1907, é que nos auxilia a ter uma visão mais ampla (não apenas "humanista") da composição que Cabral publicou em 1959, no seu livro Quaderna. Assim, conduzindo tudo isto às derradeiras consequências lógicas, não há razão para, admirando o poema, supormos que, no cosmo, o "diamante" luminoso é menos merecedor de atenção do que o "homem" e sua "cicatriz": todos eles são centrados pela realidade do universo, cada um a seu modo - e, como sujeitos, merecemos usufruir desta dupla cosmovisão e o mais que a ela associar-se, em termos científicos, poéticos ou outros.

${ }^{58}$ Entre outras coisas, podemos dizer que pensar é também "viajar" em ondas eletromagnéticas, além de sê-lo em algum (duplo) cone de luz relativístico, mesmo que um sujeito pensativo o faça quietamente sentado (caso, em que ele estará viajando no tempo).

Revista Texto Poético | ISSN: 1808-5385 | Vol. 19 (2o sem-2015) - p. 218 


\section{Referências}

CALlEGARO, Marco. O novo inconsciente. Porto Alegre: Artmed, 2011. CAMPOS, Augusto de, CAMPOS, Haroldo de, SCHNAIDERMAN. Poesia russa moderna. 6. ed. rev. ampliada. São Paulo: Perspectiva, 2001. DERRIDA, Jacques. A estrutura, o signo e o jogo no discurso das ciências humanas. In: Eduardo Prado Coelho, Estruturalismo: antologia de textos teóricos. Trad. Maria Eduarda Reis Colares et al. Lisboa: Portugália, 1968, p. 101-123.

DERRIDA, Jacques. Gramatologia. Trad. Miriam Schnaiderman e Renato Janine Ribeiro. São Paulo: Ed. da Universidade de São Paulo, 1973.

EINSTEIN, Albert. A teoria da relatividade especial e geral. 7. reimpr. Trad. Carlos Almeida Pereira. Rio de Janeiro: Contraponto, 2009.

FAUSTINO, Mário. Aeropoesia e simultaneidades. In: Artesanatos de poesia: fontes e correntes da poesia ocidental. São Paulo: Companhia das Letras, 2004.

FERGUSSON, Kitty. Stephen Hawking: aventuras de uma vida. Trad. Pedro Barros. São Paulo: Benvirá, 2012.

FREUD, Sigmund. Conferências introdutórias sobre psicanálise. Edição standard brasileira das obras psicológicas completas. Vol. XVI. Trad. José Luiz Meurer, Rio de Janeiro: Imago, 2006a, p. 281-292.

FREUD, Sigmund. Uma dificuldade no caminho da psicanálise. In: Uma neurose infantil e outros trabalhos. Edição standard brasileira das obras psicológicas completas. Vol. XVII. Trad. José Luiz Meurer. Rio de Janeiro: Imago, 2006b, p. 147-153.

MELO NETO, João Cabral de. Obra completa. Ed. org. por Marly de Oliveira com assistência do autor. Rio de Janeiro: Nova Aguilar, 1994. 
MLODINOW, Leonard. Subliminar. Trad. Cláudio Carina. Rio de Janeiro: Zahar, 2013.

PEIRCE, Charles Sanders. Collected papers. Ed. Charles Hartshorne, Paul Weiss e Arthur Burks. Cambridge, Massachusetts: Harvard University Press, 1931-1935, 1958, 8 vols. (Referidos abreviadamente como CP.)

- Semiótica. Trad. José Teixeira Coelho Netto. São Paulo: Perspectiva, 1977.

PINTO, Julio. 1, 2, 3 da semiótica. Belo Horizonte: Editora UFMG, 1995.

PRIMACK, Joel R.; ABRAMS, Nancy Ellen. Panorama visto do centro do universo. Trad. Maria Guimarães. São Paulo: Companhia das Letras, 2008.

RODITI, Itzhak. Dicionário Houaiss de fisica. Ilustrações de Veronica Françoise Teicher. Rio de Janeiro: Objetiva, 2005.

SANTAELLA, Lucia. A teoria geral dos signos: semiose e autogeração. São Paulo: Ática, 1995.

SANTIAGO, Silviano. Glossário de Derrida. Rio de Janeiro: Francisco Alves, 1976.

TELES, Gilberto Mendonça. Vanguarda europeia e modernismo brasileiro. 7. ed. com documentos da vanguarda portuguesa. Petrópolis: Vozes, 1983. VEDRAL, Vlatko. A vida em um mundo quântico. Scientific American Brasil n. 110. São Paulo: Ediouro Duetto Editorial, julho de 2011, p. 30-35 